The Aeroplane of To-morrow

By Noel Pemberton-Billing. Pp. 307.

Robert Hale, Ltd., 1941.) 12s. $6 d$. net.

$\mathrm{T}$ HIS is a difficult book to review. One does not dare to dogmatize about anything in the aeronautical world, but the seience of flight is now becoming sufficiently established to enable us to look a short way ahead with reasonable certainty. The author's conclusions as to how progress in speed or carrying capacity of heavier-than-air craft can be made, in general by an increase in wing loading, are certainly true; but the light-hearted way in which the book sweeps away, or else ignores, the attendant difficulties, rather shakes one's faith in it as a serious scientific work.

The principal part of the book is devoted to an elaboration of the author's idea of a "slip wing" aircraft, a form of assisted take-off for a highly loaded aircraft (already developed by the Short-Mayo flyingboat) evidently by his assistant, Mr. Roger Tennant, whose work he acknowledges. His figures quoted for a suggested long-range high-speed bomber are accurate aerodynamically, but in the event of a failure necessitating an emergency landing immediately after commencing a flight, the whole of the bomb and petrol loads would have to be jettisoned, and even then the author contemplates landing with a wing loading of $40 \mathrm{lb}$. per sq. foot. This is scarcely a happy procedure in the vicinity of a crowded aerodrome. This is admittedly an isolated case, but it is typical of the whole book. The best that can be said is that it puts the case of one particular avenue of possible progress in plain language such as can be read by the ordinary man, and in this sense it is useful and worth reading. One looks in vain for anything new, which the title rather leads us to expect, or anything that is not already known by serious students of aeronautics.

\section{Intermediate Inorganic Chemistry}

By Dr. J. W. Mellor. New edition, revised by Dr. H. Irving. Pp. $x x+690$. (London, New York and Toronto : Longmans, Green and Co., Ltd., 1941.) 98.

THE revision of this book has been carried out I by Dr. Irving, who states in the preface that "he has been at pains to preserve the essential character of the book". Thus, while the numerical data have been extensively revised, only minor changes have been made to the subject-matter. The reviewer feels very strongly, however, that it would have been worth the extra cost of repagination to have omitted many of the old graphical formulæ, as well as details of, for example, hyponitrous acid, hydrazoic acid and the thionic acids, which are scarcely suitable for students at this stage. Incidentally, this would have provided space for the inclusion of one or two modern processes, such as the manufacture of nitric acid from ammonia, which ought to have been mentioned in this edition. Apart from these criticisms, and perhaps the debatable point of whether it was wise to omit the electronic theory of valency, the reviser appears to have accomplished his task successfully.
Honeycraft in Theory and Practice

By J. A. Lawson. Cheaper edition. Pp. xii $+228+18$ plates. (London: Chapman and Hall, Ltd., 1940.) 3s. $6 d$. net.

THIS is a reprint of one of the best-planned books on practical bee-keeping known to the reviewer. The author perhaps allows his own preferences too much scope in his exclusive recommendation of the Italian bee, and in confining attention to the 'StoneyArcher' type of hive, although the latter, in a simplified form, is now well known and widely used under the name of 'National Standard'. The W.B.C. type -still the hive most used in Great Britain, and well suited to the climate-is dismissed in a few lines of criticism. Considerations of space would, however, probably make impossible the adequate description of more than one hive type; and the author's is a good choice.

It is to be regretted that the book has not been brought up to date in the many matters of biology and physiology, and of the physics of honey, in which knowledge has advanced since its first publication in 1931. Some of these are of practical value, and all of interest to the intelligent beekeeper. It is to be hoped that this will be remedied in a future edition.

The practical section is good, containing many useful hints and few slips. The illustrations are well chosen and produced, and really illustrate the points to which they refer. The type is large and the finish excellent, combining with the pleasing style to make the book agreeable to read.

A. D. B.

\section{Algebra}

A Text-Book of Determinants, Matrices and Algebraic Forms. By W. L. Ferrar. Pp. vii+202. (Oxford: Clarendon Press; London: Oxford University Press, 1941.) 12s. 6d. net.

7 HIS is a text-book intended primarily for undergraduates. It is designed to give a broad basis of knowledge comprising such theories and theorems in those parts of algebra which are mentioned in the titlo as are of constant application in other branches of mathematics.

The book is divided into three parts : namely, determinants, matrices, and linear and quadratic forms. It will be seen at once that there are notable omissions from the usual conception of a text-book on algebra, but the author states in the preface that these omissions are deliberate.

The arrangement of the text rather resembles a geometry in its orderly array of definitions and numbered theorems, but it must be confessed that a decimal numeration of theorems to correspond with that of the paragraphs would have greatly facilitated reference. Although the treatment throughout makes pleasant and easy reading, the author is to be particularly congratulated on his exposition of matrices, which provides just what is greatly needed in many curront applications.

There are numerous and well-chosen exercises, with occasional hints, and suggestions for further reading to build on the foundations so ably laid in this book. 